\title{
Glucose-6-phosphate dehydrogenase deficiency enhances Covid-19 infection in elderly people
}

\author{
Abdel Hafez SMN \\ Department of Histology and Cell Biology, Faculty of Medicine, Minia University, Egypt. \\ sara_histology@yahoo.com
}

\begin{abstract}
Our understanding of the mechanisms responsible for death of aged people from Covid-19 became one of the major concerns of these days. Glucose-6-phosphate dehydrogenase (G6PD) enhances the normal senescence and accelerates the precocious removal of chronologically young, yet biologically aged cells. Thus, its deficiency is associated with an increase in the cellular oxidative stress. Accumulating evidence showed that oxidative stress has a fundamental role in several age-related diseases. Nowadays, Covid-19 is considered a serious health problem worldwide. The host cellular environment is the key determinant of pathogen Infectivity. Most respiratory viral infections have a strong association with Glucose-6-phosphate dehydrogenase. Unfortunately, this enzyme deficiency markedly decreases with aging what is involved in increasing of the morbidity rate. The aim of this mini review was to shed more light on the role of G6PD deficiency in aged people infected with Covid-19 (Ref. 20). Text in PDF www.elis.sk

KEY WORDS: GSPD, Covid-19, elderly people.
\end{abstract}

\section{The epidemiology of Corona virus}

Today, the coronavirus (COVID-19) pandemic had become the most important public health problem all over the world. As of 30 March 2020, World Health Organization has documented 638,146 confirmed cases and 30,039 deaths. Unfortunately, these cases are increasing every moment. Since no one can predict the progression of this pandemic problem, social distancing, self-isolation and protection have been strongly recommended to limit the spread of this virus. COVID-19 is known as an enveloped and single-stranded RNA beta-coronavirus, which is similar to severe acute respiratory syndrome coronavirus (SARS-CoV)/SARS and Middle East respiratory syndrome coronavirus (MERS-CoV)/MERS.

\section{Pathophysiology of oxidative stress}

Free radicals are considered highly reactive atoms or molecules with one or more unpaired electron (s) in their external shell and can be formed, when oxygen interacts with certain molecules. These radicals can be formed in cells via losing or accepting a single electron, therefore, behaving as oxidants or reductants (1).

Department of Histology and Cell Biology, Faculty of Medicine, Minia University, Egypt

Address for correspondence: S. Mohammed Naguib Abdel Hafez, Department of Histology and Cell Biology, Faculty of Medicine, Minia University, Egypt.

Phone: +201061479147
The terms reactive oxygen species (ROS) and reactive nitrogen species (RNS) refer to reactive radical and non-radical derivatives of oxygen and nitrogen, respectively (2). ROS and RNS generation is not only restricted to determine deleterious effects, but it is also shared in the extraction of energy from organic molecules, in immune defence, and in the signalling process (3). Several studies documented the sources of ROS and RNS. There are endogenous and exogenous sources of ROS and RNS. Glucose-6-Phosphate Dehydrogenase (G6PD) catalyses the first, pace-making reaction of pentose phosphate cycle (PPC), which produces NADPH. NADPH maintains glutathione and thiol groups of proteins and enzymes in the reduced state, which is important for protection against an oxidative stress (4).

Accumulating evidence indicates that G6PD deficiency is considered the most common enzyme deficiency all over the world (5). Its deficiency affects nuclear cells other than those of erythrocytes thus human G6PD-deficient neutrophils displayed an impaired nitric oxide production, superoxide, and hydrogen peroxide, which could explain the defective bactericidal effect of these cells (6). Oxidative stress is known to affect viral proliferation and virulence (7). Furthermore, to being the main sources of intracellular oxidants, pulmonary cells are suitable to_8000 L of oxygen-rich air daily as well as toxic molecules (8). Many lines of evidences documented that diesel exhaust exacerbates influenza virus infections in respiratory lining epithelial (9). One condition favouring viral replication is a high oxidative stress. More ROS is produced by G6PD-knockdown cells than their normal counterparts, and cellular GSH content was lower than that of the control one in viral infection. The low level of GSH in G6PD-knockdown 
cells had been combined with low NADPH levels in these cells. As these changes in redox status of G6PD-knockdown cells are associated with an enhanced viral gene expression (7).

\section{Oxidative stress and corona}

Much evidence suggests that more production of ROS and a deprived antioxidant system can play the main role in the pathogenesis of SARS-CoV infection, associated with the progression and severity of the respiratory infections. Experimentally, severe acute respiratory syndrome showed more ROS levels and lower antioxidant levels during SARS-CoV infection (10). Some authors reported that the onset of marked respiratory damage in SARS-CoV infected patients depends on the stimulation of the oxidative stress machinery that is combined with an innate immunity and activates transcription factors, e.g. NF-kB, leading to the stimulation of pro-inflammatory host response (11). Lin and co-workers (12) suggested that SARS-CoV 3CLpro (a viral protease) made a significant increase in ROS production in HL-CZ cells, which in turn, is involved in 3CLpro-induced cell death. ROS-activated NF-kB signal transduction pathway, stimulated by SARS-CoV 3CLpro, is involved in the SARS-CoV pathophysiology (13).

\section{Oxidative stress and aging}

An increase in oxidative stress is part of normal aging process in the brain. It is well established that age related accumulated oxidative damage and a weakened antioxidant defence system led to a disturbance in the redox balance, resulting in an enhanced reacting oxygen species production. Therefore, ageing is not only associated with the changes in the adaptive immune response, but it is also involved in the pro-inflammatory state in the host. In macaques, a stronger host response in aged host was reported to virus infection than in young adult macaques, with more differential expression of genes associated with inflammation, with NF-kB as the central player (14). ROS and RNS are produced by all aerobic cells and could be the key in both aging and age-related diseases (15). It is well established that antioxidant system deprivation together with an oxidative damage accumulation occurs during ageing process.

\section{COVID-19 with aging}

The severity and mortality risk of SARS-CoV-2 infection or Covid-19 diseases have been linked with the aging process (14) and this became one of the major concerns today. Besides COVID-19 deaths in the elderly people and populations with chronic diseases, $0.9 \%$ of deaths by COVID- 19 had no confirmed chronic conditions (16). One health condition that could be enhancing mortality risk in the COVID-19 infected people is G6PD enzyme deficiency, which is the most popular enzyme deficiency all over the world affecting more than 400 million people and resulting in a variety of diseases (17). More recent study suggested that G6PD deficiency cells are suitable to infection with Human coronavirus
$(\mathrm{HCoV}) 229 \mathrm{E}$ in a higher rate compared to normal cells. Furthermore, G6PD status also share in the status and survival of other viral diseases e.g. HIV and hepatitis(18). Those particularly at risk have been the elderly and those with chronic diseases e.g. diabetes, cardiovascular diseases, cancer and chronic respiratory diseases. Indeed, these elderly people seem to be at a greater risk of dying from COVID-19 (19).

\section{Therapeutic approach}

Since it has been established that oxidative stress plays an important role in the pathogenesis of various clinical conditions and aging, several researchers had recommended investigating the therapeutic effects of antioxidant therapy. Given the important role of oxidative stress in the pathogenesis of many clinical conditions and aging, antioxidant therapy could positively affect the natural history of several diseases, while further studies are required to study the real efficacy of these therapeutic interventions (20).

\section{References}

1. Lobo V, Patil A, Phatak A, Chandra N. Free radicals, antioxidants and functional foods: Impact on human health. Pharmacognosy Rev 2010; 4: 118 .

2. Powers SK, Ji LL, Kavazis AN, Jackson MJ. Reactive oxygen species: impact on skeletal muscle. Comprehens Physiol 2011; 1: 941-969.

3. Genestra M. Oxyl radicals, redox-sensitive signalling cascades and antioxidants. Cell Signalling 2007; 19: 1807-1819.

4. Arese P, Gallo V, Pantaleo A, Turrini F. Life and death of glucose6-phosphate dehydrogenase (G6PD) deficient erythrocytes-role of redox stress and band 3 modifications. Transfus Med Hemother 2012; 39: 328-334.

5. Ho H-Y, Cheng M-L, Weng S-F, Chang L, Yeh T-T, Shih S-R et al. Glucose-6-phosphate dehydrogenase deficiency enhances enterovirus 71 infection. J Gen Virol 2008; 89: 2080-2089.

6. Tsai K-J, Hung I-J, Chow CK, Stern A, Chao SS, Chiu DT-Y. Impaired production of nitric oxide, superoxide, and hydrogen peroxide in glucose 6-phosphate-dehydrogenase-deficient granulocytes. FEBS Lett 1998; 436: 411-414.

7. Wu Y, Ho H, Cheng M, Shih S, Chiu D. Oxidative Stress And Its Role In Coronavirus 229e Infection: 100. Free Radical Biology and Medicine $2004 ; 37$.

8. Cantin AM, White TB, Cross CE, Forman HJ, Sokol RJ, Borowitz D. Antioxidants in cystic fibrosis: conclusions from the $\mathrm{CF}$ antioxidant workshop, Bethesda, Maryland, November 11-12, 2003. Free Radical Biology and Medicine 2007; 42: 15-31.

9. Ito T, Okumura H, Tsukue N, Kobayashi T, Honda K, Sekizawa K. Effect of diesel exhaust particles on mRNA expression of viral and bacterial receptors in rat lung epithelial L2 cells. Toxicol Lett 2006; 165: 66-70.

10. Van den Brand J, Haagmans BL, van Riel D, Osterhaus A, Kuiken T. The pathology and pathogenesis of experimental severe acute respiratory syndrome and influenza in animal models. J Compar Pathol 2014; 151: 83-112. 


\section{$786-788$}

11. Smith J, Willey N, Hancock JT. Low dose ionizing radiation produces too few reactive oxygen species to directly affect antioxidant concentrations in cells. Biol Lett 2012; 8: 594-597.

12. Lin C-W, Lin K-H, Hsieh T-H, Shiu S-Y, Li J-Y. Severe acute respiratory syndrome coronavirus $3 \mathrm{C}$-like protease-induced apoptosis. FEMS Immunol Med Microbiol 2006; 46: 375-380.

13. Padhan K, Minakshi R, Towheed MAB, Jameel S. Severe acute respiratory syndrome coronavirus 3 a protein activates the mitochondrial death pathway through p38 MAP kinase activation. J Gen Virol 2008; 89: 1960-1969.

14. Liu K, Chen Y, Lin R, Han K. Clinical features of COVID-19 in elderly patients: A comparison with young and middle-aged patients. $\mathrm{J}$ Infect 2020.

15. Venkataraman K, Khurana S, Tai T. Oxidative stress in aging-matters of the heart and mind. Internat J Mol Sci 2013; 14: 17897-17925.
16. Sohrabi C, Alsafi Z, O’Neill N, Khan M, Kerwan A, Al-Jabir A et al. World Health Organization declares global emergency: A review of the 2019 novel coronavirus (COVID-19). Internat J Surg 2020.

17. Ulusu NN. Glucose-6-phosphate dehydrogenase deficiency and Alzheimer's disease: Partners in crime? The hypothesis. Med Hypotheses 2015; 85: 219-223.

18. Wu Y-H, Tseng C-P, Cheng M-L, Ho H-Y, Shih S-R, Chiu DT-Y. Glucose-6-phosphate dehydrogenase deficiency enhances human coronavirus 229E infection. J Infect Dis 2008; 197: 812-816.

19. Aydemir D, Ulusu NN. Is glucose-6-phosphate dehydrogenase enzyme deficiency a factor in Coronavirus-19 (COVID-19) infections and deaths? Pathogens Global Health 2020.

20. Liguori I, Russo G, Curcio F, Bulli G, Aran L, Della-Morte D et al. Oxidative stress, aging, and diseases. Clin Intervent Aging 2018; 13: 757.

Received June 2, 2020. Accepted August 15, 2020. 